\title{
Sobre los autores
}

Javier Campo

Es doctor en Ciencias Sociales (Universidad de Buenos Aires). Investigador del CONICET. Codirector de la revista Cine Documental. Editor asociado de Latin American Perspectives. Profesor de Estética cinematográfica (UNICEN). Autor de Cine documental argentino. Entre el arte, la cultura y la política (2012), compilador de Cine documental, memoria y derechos humanos (2007) y coautor de Directory of World Cinema. Argentina (2014), World Film Locations: Buenos Aires (2014), Una historia del cine político y social en Argentina (2009 y 2011) y Reflexiones teóricas sobre cine contemporáneo (2011), entre otras publicaciones. Miembro del Centro de Investigación y Nuevos Estudios sobre Cine (FFyL-UBA), del Instituto de Investigaciones Gino Germani (FCS-UBA) y del Departamento de Historia y Teoría del Arte (Facultad de Arte, UNICEN).

\section{Ximena Triquell}

Es Magister y Doctora en Teoría Crítica por la Universidad de Nottingham y Licenciada y Profesora en Letras por la Universidad Nacional de Córdoba. Actualmente se desempeña como Profesora Titular de la materia "Cine y narrativa" de la Licenciatura en Cine y Televisión y como Prof. Adjunta a cargo de la materia "Semiótica" en la Licenciatura en Letras, ambas en la Universidad Nacional de Córdoba. Es también investigadora de CONICET.

\section{Silvana Flores}

Doctora en Historia y Teoría de las Artes por la Facultad de Filosofía y Letras de la Universidad de Buenos Aires. Ha sido becaria posdoctoral del Consejo Nacional de Investigaciones Científicas y Técnicas (CONICET) y de la Agencia Nacional de Promoción Científica y Tecnológica. Investigadora asistente del CONICET desde el 2016, con sede en el Instituto de Historia del Arte Argentino y Latinoamericano "Luis Ordaz". Es autora de El Nuevo Cine Latinoamericano y su dimensión continental. Regionalismo e integración cinematográfica (Imago Mundi, 2013), resultado de su tesis doctoral, y co-editora de Cine y Revolución en América Latina. Una perspectiva comparada de las cinematografías de la región (Imago Mundi, 2014). Ha sido docente en la Universidad de Palermo, y ha dictado cursos de grado y posgrado sobre cine argentino y latinoamericano en la UBA, integrando actualmente la cátedra de Semiología deI UBA XXI.

\section{Lior Zylberman}

Es Doctor en Ciencias Sociales, Investigador del CONICET, Investigador del Centro de Estudios sobre Genocidio (UNTREF) y Profesor Titular de Sociología en la carrera de Diseño de Imagen y Sonido (FADU, UBA). En esa casa de estudios también se desempeña como Director del Programa de Investigación en Diseño 
Audiovisual. Ha escrito numerosos artículos y capítulos de libros en torno a las problemáticas de la memoria y la imagen, la representación de los genocidios y dictaduras como también sobre cultura visual; asimismo, ha participado exponiendo sus investigaciones en diversos congresos y reuniones científicas tanto a nivel nacional como internacional.

\section{Andrea Molfetta}

(Buenos Aires, 1965) es escritora e investigadora adjunta del CONICET - Consejo Nacional de Investigaciones Científicas y Técnicas de la Argentina. Fundadora y primera presidenta de la AsAECA (Asoc.Argentina de Estudios de Cine y Audiovisual) en 2008, fue profesora visitante de universidades argentinas y brasileras. Actualmente es profesora de la Sección de Antropologia Social de la Universidad de Buenos Aires, donde dirige el grupo de investigación DOCSA - Estéticas y Políticas del Documental Sudamericano. Publica sobre arte electrónica y documental del Conosur desde 1998, siendo autora de los "Arte eletronica em Buenos Aires (1966-1993)", BsAs: Teseo, 2013, "Documental y Experimental: Ios diarios de viaje de los videoartistas sudamericanos en Francia (19841995), BsAs: Sitio del Silencio, 2014.

\section{Mariano Mestman}

Es investigador del CONICET y del Instituto Gino Germani de la Facultad de Ciencias Sociales de la UBA. Dirige la Maestría en Comunicación y Cultura en esa Facultad. Doctor en Historia del Cine por la Universidad Autónoma de Madrid (2004), realizó investigaciones posdoctorales en la Universitá degli Studi di Roma Tre (2008). Es autor de los libros Del Di Tella a Tucumán Arde. Vanguardia artística y política en el 68 argentino
(2000, junto a A. Longoni) y Estados Generales del Tercer Cine. Los Documentos de Montreal (2014). También es coordinador de los libros como Masas, pueblo y multitud en cine y televisión (2013, junto a M. Varela) y Las rupturas del 68 en el cine de América Latina (2016). Sus estudios de historia del cine latinoamericano y del Tercer Mundo fueron publicados en libros colectivos como Il Nuovo Cinema, leri e Oggi (2001), Cine documental en América Latina (2003), The Cinema of Latin America (2003), Global Neorealism. The Transnational History of a Film Style, 1930-1970 (2011), The Grierson Effect: Tracing Documentary's International Movement (2014), Political Documentary Cinema in Latin America (2014); y en journals y revistas como New Cinemas, Journal of Latin American Cultural Studies, Kilómetro 111, Letterature d'America, Secuencias, Third Text, Social Identities, entre otros. Realizó investigaciones en archivos audiovisuales de Canadá, Cuba, Italia y México.

\section{José Ángel Bergua}

Es Profesor de Sociología en la Universidad de Zaragoza (España). Ha investigado sobre conflictos medioambientales, creatividad, moda, juventud, política y distintas cuestiones teóricas y metodológicas relacionadas con lo social instituyente. Algunos de sus libros son: Patologías de la Modernidad (2005, Nóbel), Lo social instituyente (2007, PUZ), Estilos de la investigación social (2011, PUZ), Anarquías (2013, Lumen), Postpolítica (2015, Biblioteca Nueva) y Creatividad: números e imaginarios (2016, CIS)

\section{Virginia Rodríguez Herrero}

Bilbao, 1976. Profesora de Antropología y Sociología en el Centro de Enseñanza Superior Car- 
denal Cisneros (adscrito a la UCM- Universidad Complutense de Madrid). Doctora en Sociología (UA, 2010), licenciada en Antropología Social y Cultural (UCM, 2000), y en Sociología (UA, 1998). Su principal ámbito de investigación es la creación cinematográfica y los medios audiovisuales como vías de expresión, construcción de la realidad y la identidad. Autora del libro $L a$ ilusión de crear, la ilusión de creer. Reflexiones con cineastas españoles acerca del cine o la mentira necesaria (Ed. Dharana, 2015). Publicaciones diversas en la Revista OBETS (UA) o la Revista de la Academia de las Artes y las Ciencias Cinematográficas de España. Autora también de libros infantiles.

\section{Vicente Huici Urmeneta}

(Pamplona, 1955), Licenciado en Filosofía y Letras, Graduado en Historia y Neuropsicología y Doctor en Ciencias Políticas y Sociología, es Profesor Titular del Departamento de Psicopedagogía de BAM (Universidad de Deusto, Bilbao).Su obra se ha desarrollado en el ámbito de la Sociología del Conocimiento y de la Cultura, con especial atención a las cuestiones relacionadas con el espacio, el tiempo y el lenguaje. Entre sus últimas publicaciones se pueden citar: Aproximaciones a la Razón Narrativa. Historia, Novela, Autobiografía (2006); Espacio, tiempo y sociedad. Variaciones sobre Durkheim, Halbwachs, Gurvitch, Foucault y Bourdieu (2007) y Sociedad y Conocimiento. Una sonata germánica: Max Scheler, Karl Mannheim, Alfred Schutz (2009).

\section{Iñaki Martínez de Albeniz}

Es profesor de Sociología en la universidad del País Vasco-Euskal HerrikoUnibertsitatea (España) y miembro del Grupo de Investigación
Consolidado Innolab. Sus campos de especialización son la sociología política, las identidades colectivas, la sociología del arte, la gastronomía y los Estudios de Ciencia y Tecnología. Ha publicado cinco libros y numerosos artículos en revistas científicas. Colabora habitualmente en medios de comunicación escritos (El Correo Español, GARA, El Estado Mental) y audiovisuales. De entre su producción cabe destacar, en el rubro de la crítica y el análisis de la creación audiovisual, el libro: “De Anatomía de Grey a TheWire. La realidad de la ficción televisiva".

\section{Joaquín Esteban Ortega}

Doctor en Filosofía por la Universidad de Salamanca y Doctor en Teoría de la Educación por la Universidad de Valladolid. En la actualidad es profesor de Sociologíay de Movimientos Artísticos Contemporáneos en la Universidad Europea Miguel de Cervantes de Valladolid, en la que también ha ocupado durante los 10 últimos años la función de Vicerrector de Alumnos y Extensión Universitaria. Durante los 6 últimos años ha sido también codirector de las Jornadas de Cine y Filosofía realizadas en el Museo Patio Herreriano de Arte Español Contemporáneo de Valladolid.

Su trabajo se centra en la reflexión sobre las claves de la sociedad y el pensamiento contemporáneos desde un punto de vista transversal y tomando como hilo conductor las diferentes manifestaciones artísticas y culturales a partir de una perspectiva hermenéutica.

Fruto de ello son diferentes artículos de investigación publicados en revistas nacionales e internacionales y libros como Emilio Lledó. Una filosofía de la memoria (1997); Memoria, hermenéutica y educación (2002); Universidades reflexivas. Una perspectiva filosófica (2005); La condena hermenéutica (2010). 
Además ha dinamizado una intensa labor de edición a partir de diversas actividades que ha organizado en el marco del Seminario de Sociedad y Cultura contemporánea (SEMSOCU) del que fue coordinador en su universidad. Algunos de estos títulos editados son Filosofía de la educación (2006); Hermenéutica analógica en España (2008); Cultura, hermenéutica y educación (2008); Cultura contemporánea y pensamiento trágico (2009); Arte, literatura y contingencia: pensar la educación de otra manera (2009); Hermenéutica del cuerpo y educación (2009); La sociedad líquida (2009); Mercado, identidad y espectáculo en la sociedad de la cultura (2010); La aceleración: Velocidad, cultura y comunicación en los espacios urbanos contemporáneos (2011); Palabra y ficción. Literatura, pensamiento y crisis de la cultura (2011); El imaginario cinematográfico y la sociedad hipermoderna (2013); La muerte y sus imaginarios (cinematográficos) (2014); Marcas del cuerpo en educación. Imaginarios simbólicos y materiales (2014).

\section{Juan A. Roche Cárcel}

Es profesor Titular de Sociología de la Cultura y de las Artes en la Universidad de Alicante (España). Entre sus últimas publicaciones destacan, como autor, Entre el Monte de Apolo y la vid de Dioniso. Naturaleza, Dioses y Sociedad en la arquitectura teatral de la Grecia Antigua (Anthropos editorial), 2016; la Sociedad Evanescente, editorial Anthropos, 2009 (en inglés The Vanishing Society, Logos Verlag Berlin, 2013) y, como editor, Transitions. The fragility of Democracy (Logos Verlag Berlin), 2016; Espacios y tiempos inciertos de la cultura, editorial Anthropos, 2007 y La Sociología como una de las Bellas Artes. La influencia de las Artes y de la Literatura en el pensamiento sociológico, editorial Anthropos 2013. Es también autor de numerosos artículos en revistas especializadas de España, Europa, Latinoamérica y Norteamérica y coordinador de los números monográficos de la Revista Política y Sociedad, n 46, Arte y Poder, 2007, de Papers. Revista de Sociología sobre Cultura y migraciones, $n^{\circ}$ 94, 2009, de Res Publica. Revista de Filosofía Política, Transiciones. La fragilidad de la democracia, 2013, de Res Publica. Revista de Filosofía Política, Cuerpo y poder en la Grecia Antigua, 2016, y de Política y Sociedad, El saber social de los griegos antiguos. En recuerdo de Enrique Gómez Arboleya, 2016. Es, asimismo, profesor invitado, entre otras, de la Universidad Nacional del Litoral (Argentina), de la Universidad Pontifica Javeriana de Cali (Colombia) y de la Universidad de Guanajuato (México), evaluador de diversas agencias oficiales españolas $y$ argentina y de revistas españolas y argentinas de Sociología. Igualmente ha sido coordinador de investigación del área de Cultura y Artes de la ESA (Asociación Europea de Sociología) y Vicepresidente de la AESCA (Asociación Española de Sociología de la Cultura y de las Artes). Actualmente, es Co-director de la nueva colección Globalizaciones de la editorial Anthropos de Barcelona y Director del Máster de Interpretación de la Guitarra Clásica de la Universidad de Alicante. 